\title{
Which factors can influence the number of forced expiratory maneuvers on spirometry in schoolchildren?
}

\author{
Rafaela Minsky ${ }^{1}$, Janaina Scalco ${ }^{1}$, Tatiana Bobbio ${ }^{2}$, and Camila Schivinski ${ }^{1}$ \\ ${ }^{1}$ Universidade do Estado de Santa Catarina Centro de Ciencias da Saude e do Esporte \\ ${ }^{2}$ University of Saint Augustine for Health Sciences
}

June 9, 2020

\begin{abstract}
Introduction: Spirometry is of great value for understanding respiratory function and management of lung diseases. However, it presents special challenges when performed in children. Objective: To analyze factors that may influence the number of forced expiratory maneuvers required for successful spirometry in schoolchildren. Method: Healthy children aged between 6 and 12 years were tested. Forced spirometry maneuvers were conducted according to the American Thoracic Society. The children were grouped according to the number of attempts (maximum of eight). Factors that potentially influenced the number of maneuvers included: age; pulse oscillometry parameters; slow vital capacity; respiratory muscle strength; orofacial motor function, school performance, physical activity and quality of life. The Kolmogorov-Smirnov test was performed, followed by the Chi-Square, repeated measures ANOVA and Kruskal-Wallis tests. Next, multinomial logistic regression was applied. Significance level was set at 5\%. Results: 149 children (80 girls) with mean age of 9.13 years $( \pm 1.98)$ were studied. Age was related to the required number of spirometry maneuvers and children with poor school performance had a 2.84- fold greater chance of completing the exam in more than five attempts. Conclusion: Age and school performance influenced the number of forced expiratory maneuvers required for successful spirometry in schoolchildren.
\end{abstract}

\section{Hosted file}

Manuscript.doc available at https://authorea.com/users/331351/articles/458047-which-factorscan-influence-the-number-of-forced-expiratory-maneuvers-on-spirometry-in-schoolchildren

\section{Hosted file}

Table I.docx available at https://authorea.com/users/331351/articles/458047-which-factorscan-influence-the-number-of-forced-expiratory-maneuvers-on-spirometry-in-schoolchildren

\section{Hosted file}

Table II.docx available at https://authorea.com/users/331351/articles/458047-which-factorscan-influence-the-number-of-forced-expiratory-maneuvers-on-spirometry-in-schoolchildren 